the impotence of the medical observers of the Rwandan genocide. Other such tragedies are described, for instance, there is an account by a German MSF nurse of the fall of the UN "safe haven" of Srebrenica which became a "killing zone". Yet poverty and exclusion can occur just as readily in Western Europe, and MSF provides clinics for the homeless and destitute migrants there.

There follow chapters of general significance: on the protection of civilians in conflict; on the role of international medical groups in emergency relief; on international humanitarian action, and on refugees and marginalised populations. Finally there is a useful chapter on international law.

The second half of the book concerns the problem areas of Liberia, Bosnia, Chechnya, Rwanda and the Sudan. The aim of the book is to put problem situations into perspective and to draw out codes of action. One priority is the need to speak out when atrocities occur and not to defer to government manipulation of peace organisations. The case of Ethiopia, when aid organisations were manipulated as bait by an unscrupulous government, is cited. The book puts general principles - such as in maintaining the right to health, or the ethics of emergency medical assistance into the context of specific circumstances. Overall, this is a forwardlooking volume which seeks to draw constructive conclusions from current dilemmas and problems.

PAUL WEINDLING

University of Oxford, Wellcome Unit for the History of Medicine

\section{Preventing Prenatal Harm: Should the State Intervene [2nd ed]}

Deborah Mathieu, Washington DC, Georgetown University Press, 1996, 187pages, £15.50, US\$19.95.

The behaviour of a pregnant woman and even behaviour prior to pregnancy - can have a significant impact on the wellbeing of the child to be born. Not only might the future person be affected by the mode of delivery chosen by the mother, but he or she can also have his or her own health jeopardised by what the pregnant woman eats, or does not eat; the drugs and medications she takes or refuses to take, and the things she does or does not do. Although we may feel sympathy for, or even outrage on behalf of, an infant harmed in utero, it may, as Mathieu observes, be futile to force a pregnant woman to comply with certain behaviours or medical treatments when she can simply terminate the pregnancy instead. Of course, such an option would not be open to her later in pregnancy, but then interventions such as forcing her to have a caesarean section also have serious ramifications for her bodily integrity. Finally, prenatal harm can also occur in circumstances beyond the control of the pregnant woman due perhaps to her workplace conditions or environmental pollution, or caused indirectly by the funding of health and welfare benefits.

Mathieu tackles the issue of prenatal harm methodically, comprehensively and accessibly. Her book divides into seven chapters. The first outlines the problem of state intervention in prenatal harm and covers some of the prominent legal cases from the USA (not surprisingly, Mathieu predominantly uses examples from the USA) which make interesting reading in their own right. In the second chapter she looks at the bearing which the status of the fetus has on the issue. She argues that moral status could be considered irrelevant to the issue of prenatal harm since the harm in question will be experienced in the future by an individual whose status is beyond question. This does not mean that the fetus has rights either to be born or to receive medical treatment in utero. Rather, once the pregnant woman has decided to carry to term "she has not chosen to avoid a situation in which she will affect the wellbeing of another person .... and in so choosing she can be deemed to have assumed moral responsibility for at least some of the wellbeing of that future person" (page 29). Adopting this position enables Mathieu to offer a limited defence of the responsibilities of pregnant women to the unborn without threatening their access to a termination of pregnancy.

In chapters three and four she explores respectively the arguments for and against legally requiring women to act in the interests of the future child. In chapter five she looks at the practical implications of intervening during pregnancy and takes the view that there are both limits to what pregnant women (as parents) can be expected to sacrifice for their future child, but also limits to the damagem which women can be excused for. causing. Accordingly, there is som@़ ? role for the state to intervene to prevent serious harm to a fetus whicks? is going to be carried to termo However, when looking at some of the possible candidates for state interven $\overline{\bar{c}}$ tion, she points out that the relation ship between the suspected cause of harm and the harm itself must be ceres tain - which it is not in the case of cocaine use, nor can it be conclusivelyshown that heroin use is certain t $\vec{\omega}$ cause serious and lasting damage. HeR observation that the state is noo actually doing a great deal to helR pregnant drug users avoid drug use is़ echoed in her final chapter, which looks at the prenatal harms cause $\$$ indirectly by the uneven distributioro of health and welfare benefits and goods. In the penultimate chapter she, discusses the extent to which the state has been willing and able to protecE fetuses from prenatal harm in the workplace. She notes that whilst it is clearly preferable for employers to remove the threats to fetal health, Biso might not be possible. If it is not, tren preventing women from working such environments will restrict theis choices of employment. Accordingly? those women who knowingly work in hazardous conditions might find thaถ it is them, rather than their employers $\overrightarrow{\bar{B}}$ whom their future children might sue for damages. Concluding this chapter she argues that it is undesirable fo children to be permitted to sue their parents because any woman who fears] a future suit might have a termination of pregnancy instead. Her solution is more positive system of support anç rewards for those women who do have to make sacrifices for the wellbeing of their future children.

Mathieu is to be commended for her good sense and for writing a wello balanced and readable text which doe not sit too much on the fence.

HEATHER DRAPERO Centre for Biomedical Ethic त̦ The University of Birmingham

Limits. The Role of the Law in Bioethical Decision Making

Roger B Dworkin, Bloomington and $\stackrel{\mathbb{D}}{2}$ Indianapolis, Indiana University Press, 1996, 205 pages, $£ 29.50$.

Mr Dworkin discusses in this book "the law's ability to regulate new 